\title{
Wahrnehmung und Deutung des Heidnischen in Wolframs von Eschenbach „Parzival“
}

\author{
Beate Kellner
}

Erkenntnistheoretische Problemstellungen mit dem Fokus auf, Wahrnehmung und ,Deutung' haben seit einiger Zeit in der Mediävistik Konjunktur. ${ }^{1}$ Bei der Durchsicht der Forschungsbeiträge wird allerdings deutlich, dass die Begriffe nicht nur unterschiedlich, sondern mitunter auch unterminologisch verwendet werden. Sieht man von jenen Fällen ab, in denen ,Wahrnehmung' im Sinne eines bloßen Labels nichts anderes als ,Darstellung ' meint, ${ }^{2}$ wird der Begriff zum einen als ,sinnliche Wahrnehmung' definiert und in den Rahmen einer Rekonstruktion und Geschichte der Sinneswahrnehmung gestellt. Damit ist ein Forschungsfeld benannt, das im Kontext von mediengeschichtlichen und medientheoretischen Problemstellungen und damit verbunden auch von Fragen nach Körperkonzepten in der rezenten mediävistischen Forschung prominent geworden ist. Im Blick auf das Evozieren von Bilderwelten in Texten wurde hier auch ,Visualisierung' als Konzeptschlagwort eingeführt. ${ }^{3}$ Methodisch zeichnen

1 Vgl. zum Forschungsstand in der Mediävistik das Themenheft: Das Mittelalter. Perspektiven mediävistischer Forschung 8.2 (2003): Wahrnehmungs- und Deutungsmuster im europäischen Mittelalter. Hg. von Hartmut Bleumer/Steffen Patzold, darin besonders die Forschungsübersicht von dens.: Wahrnehmungs- und Deutungsmuster in der Kultur des europäischen Mittelalters, S. 4-22 - INGRID KASTEN: Wahrnehmung als Kategorie der Kultur- und Literaturwissenschaft. In: Wahrnehmung im „Parzival“ Wolframs von Eschenbach. Actas do Colóquio Internacional 15 e 16 de Novembro de 2002. Hg. von John Greenfield. Porto 2004, S. 13-36.

2 Vgl. Horst Brunner (Hg.): Die Wahrnehmung und Darstellung von Kriegen in Mittelalter und Früher Neuzeit. Wiesbaden 2000 (Imagines medii aevi 6).

3 Vgl. das Themenheft der Zeitschrift für Germanistik N. F. 9 (1999): Visualität Sichtbarkeit und Imagination im Medienwandel. Hg. von Erhard Schütz/KLausDieter Hähnel/Peter Uwe Hohendahl u.a., darin besonders: Horst Wenzel: Visualität. Zur Vorgeschichte der kinästhetischen Wahrnehmung, S. 540-556; vgl. DERs.: Hören und Sehen, Schrift und Bild. Kultur und Gedächtnis im Mittelalter. München 1995 - Haiko WandhofF: Ekphrasis. Kunstbeschreibungen und virtuelle Räume in der Literatur des Mittelalters. Berlin/New York 2003 (Trends in Medieval Philology 3). Mit problematischen Vorstellungen von unmittelbarer ,Präsenz' arbeitet Peter Czerwinski in seinen Entwürfen zu einer Geschichte der Wahrnehmung. Vgl. 
sich zwei Zugangsweisen ab: Entweder man nähert sich der Frage nach der Inszenierung von Sinneswahrnehmungen in mittelalterlichen Texten über moderne Theoriebildungen (phänomenologische und kognitionswissenschaftliche Ansätze werden allerdings bislang kaum aufgegriffen) ${ }^{4}$ oder man wählt den Zugang über mittelalterliche Wahrnehmungs- und Erkenntnistheorien, wie es JоАснім Bumke im Blick auf Wolframs von Eschenbach „Parzival“ vor einiger Zeit noch einmal exemplarisch vorgeführt hat. ${ }^{5}$

Zum anderen wird der Begriff ,Wahrnehmung' eher in Richtung von ,Deutung' verstanden oder mit ,Deutung' in eins gesetzt. Er changiert also zwischen ,Wahrnehmung' im engeren und ,Deutung' im weiteren Sinn. So verstanden lassen sich die Termini nur heuristisch voneinander trennen. Diese Übergänge manifestieren sich auch bereits in den mittelalterlichen Vorstellungen von einem Erkenntnisprozess, der sich in Stufen von der ,sinnlichen Wahrnehmung' (sensus corporeus), über die ,Vorstellungskraft' (imaginatio), den ,Verstand' (ratio), bis zur höheren und höchsten ,Einsicht' (intellectus und intelligentia) erstreckt. ${ }^{6}$ Erinnern kann man hier etwa an die für das Mittelalter grundlegenden augustinischen Ausführungen zum ,Wahrnehmen' und ,Erkennen' mit Hilfe der ,äußeren' und ,inneren Sinne' (sensus interiores und sensus exteriores). Entscheidend ist, dass die, inneren Sinne` beurteilen, was die ,äu-

Peter Czerwinski: Der Glanz der Abstraktion. Frühe Formen von Reflexivität im Mittelalter. Frankfurt a. Main/New York 1989 - DERs.: Gegenwärtigkeit, simultane Räume und zyklische Zeiten. Formen von Regeneration und Genealogie im Mittelalter. Exempel einer Geschichte der Wahrnehmung II. München 1993 - DERs.: per visibilia ad invisibilia. Texte und Bilder vor dem Zeitalter von Kunst und Literatur. IASL 25 (2000) S. 1-94. Vgl. dazu u. a. die Kritik von Peter Strohschneider: Die Zeichen der Mediävistik. Ein Diskussionsbeitrag zum Mittelalterentwurf in Peter Czerwinskis ,Gegenwärtigkeit'. IASL 20 (1995), S. 173-191 - vgl. auch die kritische Auseinandersetzung Jan-Dirk Müllers mit Thesen von Visualität und Präsenz: Jan-Dirk Müller: Visualität, Geste, Schrift. Zu einem neuen Untersuchungsfeld der Mediävistik. ZfdPh 122 (2003), S. $118-132$.

4 Es stellt sich allerdings auch die Frage, inwieweit sie für die konkrete Arbeit an mittelalterlichen Texten fruchtbar zu machen sind. Als Überblick über philosphische Modelle und Reflexionen zur Wahrnehmung sei an dieser Stelle nur verwiesen auf: Philosophie der Wahrnehmung. Modelle und Reflexionen. Hg. von Lambert Wiesing. Frankfurt a. Main 2002.

5 Jодснім Bumкe: Die Blutstropfen im Schnee. Über Wahrnehmung und Erkenntnis im „Parzival“ Wolframs von Eschenbach. Tübingen 2001 (Hermaea N.F. 94), S. 35-50 vgl. in Auseinandersetzung damit auch: Wahrnehmung im „Parzival“. Hg. von GreEnfield (wie Anm. 1). Grundlegend zur visuellen Wahrnehmung im Mittelalter noch immer: Gudrun Schleusener-Eichrolz: Das Auge im Mittelalter. 2 Bde. München 1985 (Münstersche Mittelalter-Schriften 35,1 und 35,2) - vgl. auch DAvid C. Lindberg: Auge und Licht im Mittelalter. Frankfurt a. Main 1987.

6 Ausführlich dazu: Karl Werner: Der Entwicklungsgang der mittelalterlichen Psychologie von Alcuin bis Albertus Magnus. In: Denkschriften der kaiserlichen Akademie der Wissenschaften. Phil.-hist. Classe 25. Wien 1876, S. 67-150. 
Beren Sinne' vermelden, wodurch ,höhere' Formen von Deutung und Einsicht entstehen. ${ }^{7}$

In der Mediävistik werden ,Wahrnehmung' und ,Deutung' häufig als semantisch gleitendes Begriffspaar verwendet und vielfach in neueren Arbeiten auch eingesetzt, um sich gegen die alte Form der Ereignisgeschichte abzugrenzen und deutlich zu machen, dass man die Quellen weniger im Blick auf die Rekonstruktion der geschichtlichen Wirklichkeit auswerten will, sondern vielmehr als Zeugnisse, die Aufschluss geben über Bilder, Einstellungen, Habitus, Wertungen und Erfahrungen von Wirklichkeit. ${ }^{8}$ Geleitet von der Vorstellung, dass es Bilder, Wahrnehmungs- und Deutungsformen sind, welche das Verhalten der Menschen bestimmen, richten sich die Fragestellungen der Mentalitätsgeschichte und Historischen Anthropologie auf eben diese Formen der ,Verarbeitung' von Wirklichkeit.' Auch wissenssoziologische Forschungsrichtungen akzentuieren seit langem, dass in Texten als kulturellen Zeugnissen ein ,Wissen von Wirklichkeit sedimentiert ist, welches in einem Prozess ihrer Aneignung und Konstruktion, ihrer, Wahrnehmung' und ,Deutung' entstanden ist. ${ }^{10}$ Diese Ansätze erlauben es, Themen aufzugreifen, die in sozialgeschichtlichen bzw. ereignis- und personengeschichtlichen Fragestellungen eher vernachlässigt worden sind, sie in neuen Konfigurationen zu präsentieren und die Texte dabei als Repräsentationen zu verstehen, die nicht in einem unmittelbaren Sinne als Abbilder von Wirklichkeit, sondern als deren ,Deutungen' zu verstehen sind.

7 Augustinus: „Epistula“ 147. In: CSEL 44, S. 315: cum ergo interiores oculi iudices sint exteriorum oculorum, isti autem illis quodam officio nuntiandi et ministerio famulentur multaque illi uideant, quae isti non uident, nibil isti uideant, unde non illi tamquam praesides iudicent, quis non illos istis incomparabili aestimatione praeponat?

8 Vgl. aus der Perspektive der Geschichtswissenschaft die Forschungsübersicht bei HansWerner Goetz: Wahrnehmungs- und Deutungsmuster als methodisches Problem der Geschichtswissenschaft. In: Wahrnehmungs- und Deutungsmuster. Hg. von Bleumer/ Patzold (wie Anm. 1), S. 23-33.

9 Vgl. in der germanistischen Literaturwissenschaft die noch immer grundlegenden Forschungsberichte von CHRistian KIENING: Anthropologische Zugänge zur mittelalterlichen Literatur. Konzepte, Ansätze, Perspektiven. In: Forschungsberichte zur Germanistischen Mediävistik. Hg. von Hans-Jochen Schiewer. Bern/Berlin/Frankfurt a. Main u. a. 1996 (Jahrbuch für Internationale Germanistik, Reihe C, 5/1), S. 11-129Ursula Peters: Historische Anthropologie und mittelalterliche Literatur. Schwerpunkte einer interdisziplinären Forschungsdiskussion. In: FS Walter Haug und Burghart Wachinger. Hg. von Johannes Janota/Paul Sappler/Frieder Schanze u.a. 2 Bde. Tübingen 1992, Bd. 1, S. 63-86 - vgl. dazu etwa auch den Band: Wahrnehmen und Handeln. Perspektiven einer Literaturanthropologie. Hg. von Friedmar Apel/Wolfgang Braungart/Klaus Ridder. Bielefeld 2004.

10 Vgl. bereits Peter L. Berger/Thomas Luckmann: Die gesellschaftliche Konstruktion der Wirklichkeit. Eine Theorie der Wissenssoziologie. Frankfurt a. Main 1969 - PetER L. Berger: Zur Dialektik von Religion und Gesellschaft. Elemente einer soziologischen Theorie. Frankfurt a. Main 1973, prägnant S. 4. 
Hier möchte ich meine Ausführungen situieren und mich Formen der, Wahrnehmung' und ,Deutung' des Heidnischen im Mittelalter aus literaturwissenschaftlicher Perspektive nähern. Zugrunde liegt die methodische Annahme, dass die Literatur, welche mehr als andere Redeordnungen (etwa die Historiographie oder das Recht) von einer unmittelbaren Wirklichkeitsreferenz entlastet ist, geradezu prädestiniert dafür scheint, verschiedenste Konstellationen der Begegnung von Kulturen, von Eigenem und Fremdem durchzuspielen: Auf der Ebene literarischer Sinnsysteme können, so die Hypothese, utopische Potentiale ebenso ausgelotet werden wie Szenarien des Konflikts auf die Spitze getrieben. Im folgenden sollen eben jene Spielräume und Möglichkeiten der ,Deutung' des Fremden in der Literatur - exemplarisch - untersucht werden.

Literarische Texte führen auf eine Schicht der vergangenen Kultur, die sich nicht additiv mit dem in anderen Diskursen (wie dem Recht oder der Theologie) sedimentierten Wissen verrechnen lässt. Sie können dabei die in anderen Diskursen kodierten Kulturmuster, Normen und Leitbilder aufgreifen, doch sie wiederholen diese nicht nur in ihrer Sprache, sondern modifizieren, konfigurieren und transgredieren sie, ja gestalten sie in ihrer eigenen Weise im Rahmen ihrer eingespielten Sprechmuster, ihres Gattungssystems, ihrer Bau- und Kommunikationsformen. Wenn nun danach gefragt werden soll, wie fremde Kulturen in der volkssprachigen Literatur des Mittelalters wahrgenommen und gedeutet werden, so zielt diese Problemstellung einerseits auf epistemische Konstellationen und kulturelle Semantiken, denn sie fragt nach dem in der Literatur präsentierten Wissen über das Fremde, nach Mustern und Modellen der Wahrnehmung- und Deutung, nach Bewertungen, (Vor-)urteilen, nach Übertragungen des Eigenen auf das Fremde und des Fremden auf das Eigene. ${ }^{11}$ Doch andererseits zielt sie - unter literaturwissenschaftlichem Fokus - auf die spezifisch literarischen Verfahren der Inszenierung des Fremden.

Konkret werde ich unter den genannten Problemstellungen Begegnungen zwischen Heiden und Christen, Verschränkungen von Heidnischem und Christlichem, in Wolframs „Parzival“ untersuchen, denn hier werden Prozesse der Integration und Desintegration von Kulturen, der Auseinandersetzungen zwischen Orient und Okzident, auf vielfache Weise verhandelt. Nun zeigt sich, dass in den epischen Texten Wolframs nicht nur eine Fülle von Begegnungen

11 Vgl. zur Problematik von Fremd- und Selbstverstehen in phänomenologischer Tradition etwa: Alfred Schütz: Grundzüge einer Theorie des Fremdverstehens. In: Ders.: Der sinnhafte Aufbau der sozialen Welt. Frankfurt a. Main 1974, S. 137-197 - Bernhard Waldenfels: Der Stachel des Fremden. Frankfurt a. Main $1991^{2}$ - DERs.: Topographie des Fremden. Studien zur Phänomenologie des Fremden 1. Frankfurt a. Main 1997 vgl. dazu in ethnologischer Perspektive etwa auch Clifford Geertz: Dichte Beschreibung. Beiträge zum Verstehen kultureller Systeme. Frankfurt a. Main $1994^{3}$. 
zwischen der christlichen und der islamischen Welt zum Thema wird, sondern dass sich über Verschränkungen zwischen Christlichem, Heidnischem und Höfischem immer wieder Konstrukte ergeben, die man zumindest heuristisch als ,Hybride' bezeichnen könnte. Gemeint sind Strukturen und Phänomene, welche durch komplexe Überlagerungen des Heidnischen, Christlichen, Höfischen und Mythischen gekennzeichnet sind. In Wolframs epischen Texten sowie auch in jenen der Wolfram-Tradition kommt es zu Überblendungen des Christlichen und Heidnischen, die nicht mehr in einer Dichotomie von ,christlich' und ,heidnisch' oder in einer Semantik von ,gut' und ,böse' auflösbar sind. Dies manifestiert sich auf der Ebene der zentralen christlichen Symbole wie dem Gral ebenso wie in den christlichen und höfischen Rollen- und Gesellschaftsbildern.

Gerade die genauere Betrachtung solcher ,Hybriden ${ }^{12}$ legt offen, wie problematisch die auch heute noch weit verbreitete Vorstellung von einer monolithisch christlichen Kultur des abendländischen Mittelalters ist. Mit dem Begriff des ,Hybriden' kann man versuchen, die verschiedenen Aggregatszustände und Konglomerate von Heidnischem, Mythischem und Christlichem zu fassen, ohne das Material a priori in die Modelle von christlicher Oberfläche und mythisch-heidnischer Tiefe, von christlichen und mythischen Schichten, oder von Dichotomien zwischen dem Christlichen und Mythischen respektive dem Christlichen und Heidnischen zu pressen. Mit dem Begriff des ,Hybriden' soll daher nicht danach gefragt werden, ob ein Phänomen ,letztlich` heidnisch, mythisch oder christlich ist. Indem den vielfältigen Verschränkungen, aber auch Spannungen von Heidnischem, Mythischem und Christlichem über die Vorstellung des ,Hybriden' Rechnung getragen wird, sollen die jeweils betrachteten Phänomene und Strukturen gerade nicht monokausal erklärt werden. Wenn in den literarischen Inszenierungen des ,Hybriden` Brüche und Diskontinuitäten, Aporien und Paradoxien erkennbar sind, sollen diese in den Analysen exponiert und nicht geglättet werden.

Zwei Ebenen der Untersuchung des „Parzival“ haben sich damit unter den Aspekten von Wahrnehmung und Deutung des Heidnischen und Fremden herauskristallisiert, erstens die Frage nach den vielfachen Formen der Begegnung

12 An dieser Stelle sei nur verwiesen auf Ausführungen Michail Bachtins, welche einen wichtigen Bezugspunkt der Reflexion des Begriffes darstellen. Vgl. besonders ders.: Das Wort im Roman. In: Ders., Die Ästhetik des Wortes. Hg. und eingeleitet von RaINer GrüBEL. Frankfurt a. Main 1979, S. 154-300, hier S. 195: „Wir nennen diejenige Äußerung eine hybride Konstruktion, die ihren grammatischen (syntaktischen) und kompositorischen Merkmalen nach zu einem einzigen Sprecher gehört, in der sich in Wirklichkeit aber zwei Äußerungen, zwei Redeweisen, zwei Stile, zwei ,Sprachen', zwei Horizonte von Sinn und Wertung vermischen. Zwischen diesen Äußerungen, Stilen, Sprachen und Horizonten gibt es [...] keine formale - kompositorische und syntaktische - Grenze; [...].“ 
von Heidnischem und Christlichem in Wolframs Roman und zweitens, eng damit verbunden, die Frage nach dem ,Hybriden`.

\section{III}

Das Fremde, das Heidnische und Orientalische, ${ }^{13}$ kommt in Wolframs figurenreichem Universalroman auf der Handlungsebene zunächst in den Erzählungen von Parzivals Vater Gahmuret ins Spiel, also in eben jenen Teilen des Romans, die Wolfram über seine Quelle, Chrétiens de Troyes' „Conte du Graal“, hinaus hinzufügt und die gerade auch deshalb als besonders signifikant für seine Konzeption zu betrachten sind..$^{14}$ Erbe- und vaterlos - wie später auch Parzival - fasst Gahmuret den Entschluss, in die Welt hinauszuziehen, um Ehre (prîs, 7,22) zu erringen. Da er sich aus Stolz nur dem Gefolge des höchsten Herrn der Welt anschließen will, begibt er sich im Orient in den Dienst jenes von Wolfram als bâruc $(13,21)$ bezeichneten heidnischen Herrschers, den man historisch gesehen - mit dem Kalifen von Bagdad identifizieren kann. ${ }^{15}$

13 Vgl. dazu zuletzt Arthur Groos: Orientalizing the Medieval Orient. The East in Wolfram von Eschenbach's „Parzival“. In: Kulturen des Manuskriptzeitalters. Ergebnisse der Amerikanisch-Deutschen Arbeitstagung an der Georg-August-Universität Göttingen vom 17. bis 20. Oktober 2002. Hg. von Arthur Groos/Hans-Jochen Schiewer. Göttingen 2004 (Transatlantische Studien zu Mittelalter und Früher Neuzeit 1), S. 61 86 - vgl. dazu Hans Szkrenar: Studien zum Bild des Orients in vorhöfischen deutschen Epen. Göttingen 1966 (Palaestra 243) - Hermann Goetz: Der Orient der Kreuzzüge in Wolframs „Parzival“. Archiv für Kulturgeschichte 49 (1967) S. 1-42 Roy Wisbey: Wunder des Ostens in der „Wiener Genesis“ und in Wolframs „Parzival“. In: Studien zur frühmittelhochdeutschen Literatur. Cambridger Colloquium 1971. Hg. von L. Peter Johnson/Hans-Hugo Steinhoff/Roy A. Wisbey. Berlin 1974, S. 180-214 - Paul Kunitzsch: Die Arabica im „Parzival“ Wolframs von Eschenbach. Wolfram-Studien II (1974) S. 9-35 - DERs.: Quellenkritische Bemerkungen zu einigen Wolframischen Orientalia. Wolfram-Studien III (1975), S. 263-275 - DERs.: Erneut: Der Orient in Wolframs „Parzival“. ZfdA 113 (1984), S. 79-111.

14 Zitiert wird nach: Wolfram von Eschenbach: „Parzival“. Studienausgabe. Berlin 1965 (unveränderter Nachdruck der 6. Ausgabe von Karl Lachmann). Vgl. dazu Wolfram von Eschenbach: „Parzival“. Studienausgabe. Mittelhochdeutscher Text nach der sechsten Ausgabe von Karl Lachmann. Übersetzung von Peter Knecht. Berlin/New York 1998; Wolfram von Eschenbach: „Parzival“. 2 Bde. Nach der Ausgabe Karl Lachmanns revidiert und kommentiert von Eberhard Nellmann. Übertragen von Dieter KüHN. Frankfurt a. Main 1994 (Bibliothek deutscher Klassiker 110. Bibliothek des Mittelalters 8.1 und 8.2).

15 Als Sitz des abbasidischen Kalifen war Bagdad im 10. und 11. Jahrhundert das geistige und ökonomische Zentrum des Islam. Vgl. Nellmann: Kommentar (wie Anm. 14), S. 461. Die Situation im Reich des Kalifen bestimmen nach der Darstellung des Erzählers im „Parzival“ nicht kriegerische Auseinandersetzungen von Heiden und Christen, sondern Konflikte zwischen heidnischen Reichen (14,3-7). 
Gahmurets Aufnahme in den Dienst beim bâruc wird vom Wechsel seines Wappens begleitet: Statt des Panthers derer von Anschouwe führt er nun einen Anker als Zeichen der Hoffnung auf ein Ziel seiner rastlosen Ritterschaft im Wappen (14,12-17). Und gerade dieser Austausch des Wappens bringt die Herauslösung Gahmurets aus dem ihm angestammten Verwandtschaftsverband und dem heimatlichen Raum noch einmal zeichenhaft zum Ausdruck. Er zeigt den Aufenthalt im Heidenland, in dem Gahmuret aller Orten Ruhm erringt, als eine Zäsur. Zwei Drittel der Welt, so berichtet der Erzähler, seien Gahmurets neuem Herrn untertan gewesen:
im wart gesagt, ze Baldac
ware ein sô gewaltic man,
daz im der erde untertân
diu zwei teil waren oder mêr.
sîn name heidensch was sô hêr
daz man in hiez den bâruc.
er hete an krefte alsolhen zuc,
vil künege wâren sîne man,
mit krôntem lîbe undertân. (13,16-24)

Der bâruc wird dabei nicht nur als weltliches, sondern auch als geistliches Oberhaupt der Heiden geschildert: Als oberster Würdenträger der heidnischen Religion wird er in Analogie zum christlichen Papst gesetzt, was sich auch auf seine Amtsgewalt bezieht, denn jenem wird nach der heidnischen Ordnung wie dem Papst die Binde- und Lösegewalt unterstellt, was im Text als bâbestreht $(13,29)$ bezeichnet wird. Wie der Papst kann jener daher Ablass für die Sünden gewähren: der bâruc in für sünde | gît wandels urkünde $(14,1 \mathrm{f}$.). Diese knappen Passagen zeigen komplexe Übertragungen, die für die Konzeption des Romans kennzeichnend sind: Man sieht, dass Wolfram nicht nur seine Vorstellungen von weltlicher Herrschaft und vasallitischer Bindung auf den Orient überträgt, sondern dass er auch die fremde Religion als Analogon zur christlichen beschreibt. Nähe und Ferne verschränken sich in dieser Art der Inszenierung. Rom und Bagdad, der Papst und der bâruc werden so parallelisiert (13,26-14,2), dass das Ferne des Orients in den Kategorien der eigenen Ordnungen als vertraut erscheinen kann. Der bâruc, so ließe sich pointieren, wird zur Chiffre, zum hybriden Konstrukt, in dem sich Christliches und Islamisches verschränken. 
Im Zuge seiner ritterlichen Fahrten in der heidnischen Welt gelangt Gahmuret nach Zazamanc, ins Land der schwarzen Königin Belakane, welche mit Krieg bedrängt wird. ${ }^{16}$ Er zieht mit großem Pomp in die Stadt Patelamunt ein, was seinen ritterlichen Körper, seine Aura, zur Schau stellt und den Kontrast unterstreicht zwischen seiner glänzenden Erscheinung und der schwarzen Farbe der Einwohner. ${ }^{17}$ Wiederholt wird auf jene hingewiesen, und zwar durchaus auch in abschätzigem Sinn: liute vinster sô diu naht $\mid$ wârn alle die von Zazamanc: b̂̂ den dûht in diu wîle lanc $(17,24-26) .{ }^{18}$ Dementsprechend wird auch das Aussehen der Königin in deutlicher Distanz zu höfischen Schönheitsidealen beschrieben, ${ }^{19}$ sie selbst befürchtet, der schöne Fremde könne an ihrer schwarzen Hautfarbe Anstoß nehmen: ôwî wan tate im daz niht wề! | daz het ich gerne erfunden $\hat{e}$ (22,9 f.). Topiken von der hitzigen Art der Schwarzen entsprechend verliebt sich Belakane unverzüglich in den hellhäutigen Ritter $(23,22-28)$, und sobald jener die Feinde in großartigem Kampf besiegt hat, ${ }^{20}$ übergibt sie ihm ihren Leib und ihr Reich. Doch auch als das Paar miteinander im Bett liegt, versäumt es der Erzähler nicht, auf den Unterschied ihrer Hautfarbe hinzuweisen:
dô phlac diu küneginne
einer werden süezer minne,
und Gahmuret ir herzen trût.
ungelîch was doch ir zweier hût. (44, 27-30)

Das die Liebe überstürzende Verhalten der Königin will nicht recht zu ihrer früheren - in der Erzählung betonten - Zurückhaltung passen. Jene erscheint als eine widersprüchliche Person, was sich auch und vor allem in der von Gahmuret

16 Belakane hat Isenhart in überspannter höfischer Minne hingehalten, bis er in ihrem Dienst den Tod fand. Seine Verwandten rächen sich nun an ihr mit einem Kriegszug. Vgl. „Parzival“, 16,1-18; 26,1-28,9.

17 Vgl. Alfred Ebenbauer: Es gibt ain mörynne vil dick susse mynne. Belakanes Landsleute in der deutschen Literatur des Mittelalters. ZfdA 113 (1984), S. 16-42.

18 Vgl. „Parzival“, 19,17-19: Swaz dâ was volkes inne, | More und Morinne | was beidiu wîp unde man. Ebd., 20,4-6: manege tunkele frouwen | sach er bêdenthalben sîn:| nâch rabens varwe was ir schin. Vgl. auch ebd., 20,24-26.

19 „Parzival“, 24,6-12: ist iht liehters denne der tac, | dem glîchet niht diu künegin. | si hete wîplîchen sin, | und was abr anders rîterlîch, | der touwegen rôsen ungelîch. | nâch swarzer varwe was ir schîn, | ir krône ein liehter rubîn.

20 Am Kampf nehmen zahlreiche Ritter der westlichen Welt teil. Auch das Motiv des Verwandtenkampfes, das im weiteren Verlauf des Romans zentral wird, klingt bereits an, als Gahmuret auf seinen Vetter König Kaylet und dessen Neffen Killirjacac trifft. Kaylet steht auf der Seite der Partei Isenharts, da er seinerseits mit dem Schottenkönig Vridebrant verwandt und über Vridebrant, der wiederum der Cousin von Belakanes Minneritter Isenhart ist, mit den Verwandten Isenharts verbunden $(28,21-26 ; 46,20$ $47,25 ; 48,7-28)$ ist. 
beobachteten Differenz zwischen ihrer schwarzen Hautfarbe und ihrer inneren weiblichen Reinheit und Vorbildlichkeit manifestiert: Innen- und Außenseite entsprechen sich nicht. ${ }^{21}$ Belakanes Ethos ist höfisch und christlich zugleich, doch eine Christin ist sie nicht, die Vorstellung von einer anima naturaliter christiana drängt sich auf. Der Erzähler forciert diese Nähe der Heidin zum Christentum, indem er sozusagen die Perspektive von Gahmurets Wahrnehmung verlängert:

Gahmureten dîhte sân, swie si ware ein heidenin, mit triwen wîplìcher sin in wîbes herze nie geslouf. ir kiusche was ein reiner touf, und ouch der regen der si begôz, der wâc der von ir ougen flôz uf ir zobel und an ir brust. $(28,10-17)$

Sowohl ihre weibliche kiusche wie ihre Tränen werden mit der Taufe gleichgesetzt. Die Körperflüssigkeit wird zum Substitut des Taufwassers erklärt, ${ }^{22}$ das eigene Ethos, die eigene Körperlichkeit scheinen in dieser Darstellung den sakramentalen Akt der Taufe zu ersetzen - eine theologisch betrachtet ungeheure Aussage, die wohl nur in der Literatur möglich war. Und auch im Fortgang der Erzählung wird Belakanes Heidentum noch einmal anders perspektiviert: Als Gahmuret Belakane verlässt, weil er von der Sehnsucht nach neuen ritterlichen Taten getrieben wird, insistiert er in seinem Abschiedsbrief auf ihrem Heidentum, er nutzt die Glaubensdifferenz, um sein Verhalten zu legitimieren (55,2156,26). Wenn hier im Kontrast zu den eben analysierten Passagen die Glaubensunterschiede stark gemacht werden, so relativiert sich dies auf der anderen Seite dadurch, dass es sich um nichts als Ausreden für ein wenig ehrbares männliches Verhalten handelt, um Aussagen einer Figur, die keinesfalls mit der Erzählerperspektive kurzgeschlossen werden können. ${ }^{23}$

Die Erzählung lässt sich also nicht festlegen auf eine Sicht, hakenschlagend, um auf den Prolog des Romans zu verweisen (1,18 f.), entzieht sie sich jedem Zugriff. Dies wird einmal mehr auch an Belakanes Reaktion auf Gahmurets Brief offenbar, denn sie zeigt sich sogleich zur Taufe bereit und macht so, in erster Lesart deutlich, wie hinfällig dessen Einwände sind. Auf der anderen Seite betont gerade ihre Rede die innere Distanz zum Christentum, denn die Taufe wäre für sie lediglich ein Mittel zum Zweck, um den Geliebten zurückzuge-

21 Die Relation von innen und außen ist ein Thema, das Wolfram durch den Roman hindurch verfolgt. Vgl. Bumke (wie Anm. 5), prägnant S. 1-27.

22 Vgl. Louise Gnädinger: Wasser - Taufe - Tränen. (Zu Parz. 817,4-30). In: WolframStudien II (1974), S. 53-71 - Bumke (wie Anm. 5), S. $61 \mathrm{f}$.

23 Später wertet auch Herzeloyde Belakane als Heidin ab, als sie Gahmuret für sich beansprucht; vgl. 94,11-16. 
winnen: ,ôwê wie balde daz geschiht! | wil er wider wenden, | schiere sol ichz enden" (56,28-30). Fast chiastisch weist eine Passage auf die andere zurück: Korrespondiert hier die innere Ferne zum Christentum mit der Bereitschaft zum äußeren Vollzug des Sakraments, so wurde dort die innere Nähe zum Christentum als Pendant zur Taufe inszeniert. Die Episoden um Belakane umkreisen die Problematik von Nähe und Distanz zwischen Heiden und Christen, ohne diese eindeutig zu perspektivieren.

Unter anderen Vorzeichen wird jene Thematik auch beim Tod des Grenzgängers Gahmuret bedeutsam. Bei seiner zweiten Eheschließung mit Herzeloyde, der späteren Mutter Parzivals, bittet sich jener aus, weiterhin ritterliche Fahrten unternehmen zu dürfen $(97,7-10){ }^{24}$ Während einer Orientfahrt, als er erneut auf Seiten des bâruc kämpft, wird er schließlich durch feige heidnische List getötet. ${ }^{25}$ Es können hier nicht alle Aspekte seines Todes en détail analysiert werden, ich konzentriere mich auf das Begräbnis, näherhin die Begräbnisse, welche der Ritter als einer erfährt, der die Grenzen zwischen Orient und Okzident mehrfach überschritten hat, der mit einer heidnischen und einer christlichen Frau verheiratet war und der Nachkommen im Osten und im Westen zeugte.

Prunkvoll wird sein Leichnam im Orient bestattet, in Bagdad, im Zentrum der islamischen Welt (106,29-108,28). Der bâruc scheut keine Kosten, man balsamiert den Toten ein, reich wird das Grab verziert und auf Bitten der christlichen Mitstreiter Gahmurets lässt er ein Kreuz errichten, auf welchem man den Helm mit einem Epitaph anbringen kann. Das christliche Symbol des Kreuzes wird also, unverstanden von den Heiden, wie es im Text heißt, auf dem Grab eines Christen errichtet, der im Orient im Dienst des mächtigsten heidnischen Herrschers fiel. Zudem beten die Heiden Gahmuret als Gott an, der Christ wird offensichtlich dem heidnischen Götterhimmel zugerechnet, den man dem monotheistischen Islam im Mittelalter unterstellt. Es versteht sich, dass dies als stärkster Ausdruck seiner Wertschätzung im Orient gelten kann:

ez betent heiden sunder spot

an in als an ir werden got,

nibt durch des kriuzes êre

24 Es ist ein Zeichen der besonderen Liebe des Paares, dass Gahmuret in diesen Kämpfen stets eines von Herzeloydes Hemden über seine Rüstung zieht, und dass sie jenes, so wie er es wiederbringt, durchstochen $(101,14)$ und zerhouwen $(101,15)$, nach seiner Rückkehr über der bloßen Haut trägt (101,9-20).

25 Vgl. „Parzival“, 105, 16-24. Ein Heide weicht seinen Helm mit Bocksblut auf, weshalb ein Speer seinen Kopf durchbohren kann. 
noch durch des toufes lêre,

der zem urteillîchen ende

uns losen sol gebende. (107,19-24)

Das Grab in Bagdad ist, so hat es sich gezeigt, eine hybride Konstruktion, die heidnische und christliche Elemente und Ansprüche im Zeichen höfischen Prunks zu vereinen sucht. Es lässt die heidnische Verehrung ebenso zu, wie es Gahmurets eigentlicher Herkunft aus dem Christentum durch die Errichtung des Kreuzes Rechnung trägt.

Sterbend hatte jener noch befohlen, Herzeloydes Hemd, das er wie stets in seinen Kämpfen über seiner Rüstung trug, und den Speer, der ihn getötet hatte, seiner Frau zu bringen (106,23 f.). Die Dame fragt nach dem Speer und wie immer will sie das zerfetzte, blutige Hemd ihres Mannes, nun im Sinne einer Vergegenwärtigung des Verstorbenen, auf ihrem Leib tragen, die Zäsur des Todes in gewissem Sinne negierend $(111,14-28)$. Doch man nimmt ihr beides und bestattet, wie es mit metonymischen Ausdrücken heißt, den sper und ouch daz bluot $(112,1)$ im Münster, genauso, wie einen Toten sô man tôten tuot $(112,2){ }^{26}$ Es sei dahingestellt, ob man Speer und Blut hier als Reliquien auffassen kann.

Jedenfalls wird Gahmuret - und das erscheint mir spektakulär - gewissermaßen zweimal bestattet, im Orient und im Okzident, in der Ferne und der Heimat. Zugleich relativiert sein Lebensweg - wie die beschriebenen Akte seines Begräbnisses - die Begriffe von Ferne und Nähe, von Fremde und Heimat: Wo ist die eigentliche Heimat dieser Figur an den Grenzen? Gibt es noch di e Heimat für Gahmuret nach seinem Weggang aus dem väterlichen Königreich, in welches er - dies ist bezeichnend - nie mehr zurückkehrt? Gibt es Fremde für jenen, der sein Wappenzeichen, seinen Anker, überall in der Welt herumgeführt hat? Und wo liegt die Grenze zwischen Christen und Heiden, wenn jene ein Kreuz auf dem Grab dessen errichten, den sie als Gott verehren? Noch komplexer stellt sich der Text dar, wenn man Herzeloydes Handlungen und Reflexionen nach Gahmurets Tod und der Geburt des gemeinsamen Sohnes Parzival einbezieht (113,1-114,4): Sie stilisiert sich selbst mit deutlichen Anklängen an die Mutter Gottes, näherhin die Figur der regina lactans, ${ }^{27}$ sie identifiziert ihren Sohn Parzival mit dem Vater Gahmuret, sie transzendiert den Geburtsvorgang in heilsgeschichtliche Zusammenhänge und sie rückt Parzivals Geburt auf diese

26 Vgl. zur Passage auch die perspektivenreiche Interpretation von BRUnO QUAST: Diu bluotes mâl. Ambiguisierung der Zeichen und literarische Programmatik in Wolframs von Eschenbach „Parzival“ . DVJs 77 (2003), S. 45-60, hier S. 49-51. Quast versteht Blut und Speer als „(Berührungs)Reliquien“ (S. 50).

27 Vgl. Karl Bertau: Regina lactans. Versuch über den dichterischen Ursprung der Pietà bei Wolfram von Eschenbach. In: Ders.: Wolfram von Eschenbach. Neun Versuche über Subjektivität und Ursprünglichkeit in der Geschichte. München 1983, S. 259285. 
Weise in die Nähe der Geburt Jesu. Dem im Orient von den Heiden als Gott verehrten Gahmuret kommt hier die Rolle des Vaters der Erlöserfigur zu.

\section{VI}

Obgleich der Bund zwischen der schwarzen Königin Belakane und dem weißen Ritter Gahmuret schon nach kurzer Zeit gelöst worden ist, manifestiert sich ihre Verbindung in ihrer Genealogie, in jenem Sohn, den Belakane bereits unter dem Herzen trägt, als Gahmuret sie heimlich verlässt: ${ }^{28}$ in Feirefiz, dem Halbbruder Parzivals. Seine schwarz-weiß gefleckte Haut, die ebenso mit einem beschriebenen Pergament ${ }^{29}$ verglichen wird wie sie mit Blick auf das Elsterngleichnis des Prologs als elsternfarbig $(57,27)$ bezeichnet wird, zeigt als Schauseite seines Körpers seine Herkunft. Gahmuret akzentuiert in seinem Abschiedsbrief seine eigene Genealogie, um dem Nachkommen das Wissen um die väterliche Linie zu sichern. ${ }^{30}$

Mit dem Genealogischen, welchem in den epischen Texten Wolframs eine tragende Rolle zukommt, ist ein zentrales mittelalterliches und frühneuzeitliches Modell der Weltdeutung angesprochen, das gleichermaßen als Macht- und Wissensdispositiv fungiert. ${ }^{31}$ Den figurenreichen Doppelroman um die beiden Protagonisten Parzival und Gawan durchzieht nicht nur ein dichtes Netz von verwandtschaftlichen Beziehungen, sondern es wird auch immer wieder thematisiert, dass und inwiefern Genealogie eine Ordnung des Blutes un d des Wissens darstellt. ${ }^{32}$ Daher versteht es sich, dass das Wissen um seine Genealogie,

28 „Parzival“, 57,1 $\mathrm{f}$.

29 "Parzival“", 747, 25-28: dô sprach Herzeloyden kint | , als ein geschriben permint, | swarz und blanc her unde dâ, | sus nante mirn Eckubâ.'

30 „Parzival“, 56,1-24. Wie auch die Rezipienten an dieser Stelle erstmals erfahren, führt diese Genealogie von Gahmuret über Gandin, Addanz, Lazaliez bis zum Ahnherrn Mazadan und der Fee Terdelaschoye.

31 Vgl. dazu mit weiteren Hinweisen: Beate Kellner: Ursprung und Kontinuität. Studien zum genealogischen Wissen im Mittelalter. München 2004.

32 Vgl. zur Genealogie im „Parzival“ etwa: Karl Bertau: Versuch über Verhaltenssemantik von Verwandten im „Parzival“ (1978). In: Ders.: Wolfram von Eschenbach. Neun Versuche über Subjektivität und Ursprünglichkeit in der Geschichte. München 1983, S. 190-240 - Werner Busse: Verwandtschaftsstrukturen im „Parzival“. In: WolframStudien V (1979), S. 116-134 - Elisabeth SCHMid: Familiengeschichten und Heilsmythologie. Die Verwandtschaftsstrukturen in den französischen und deutschen Gralromanen des 12. und 13. Jahrhunderts. Tübingen 1986 (Beihefte zur Zeitschrift für romanische Philologie 211), zu Wolframs von Eschenbach „Parzival“, S. 171-204 Helmut Brall: Familie und Hofgesellschaft in Wolframs „Parzival“. In: Höfische Literatur, Hofgesellschaft, Höfische Lebensformen um 1200. Hg. von Gert Kaiser/JANDirk MüLlER. Düsseldorf 1986 (Studia humaniora 6), S. 541-583 - DERs.: Gralsuche und Adelsheil. Studien zu Wolframs „Parzival“. Heidelberg 1983 (Germanische Bi- 
welches ihm der scheidende Gahmuret gleichsam als väterliches Erbe hinterlässt, ganz maßgeblich für Feirefiz sein wird. Ihm, der als Halbbruder einer der nächsten Angehörigen Parzivals ist, kommt im genealogischen Gesamtsystem des Textes eine gewichtige Rolle zu, denn mit Gahmuret greift die Mazadansippe in den Orient aus, in Feirefiz verschränken sich Osten und Westen, Heidentum und Christentum genealogisch. Mit Feirefiz werden mächtige Heiden und mächtige Christen zu nahen Verwandten. Das Genealogische wird im Text somit als zentrales Integrationsmodell verschiedener Kulturen, als zentrales Integrationsmodell des Heidnischen und Christlichen genutzt. Von besonderer Bedeutung ist dabei, dass die genealogische Verbindung zwischen Westen und Osten über die Vereinigung des Blutes als Naturordnung inszeniert und gedeutet werden kann. Konstituiert wird ein Familienzusammenhang, dessen Bindungen in den epischen Welten Wolframs in aller Regel wichtiger, stabiler und dauerhafter sind als gesellschaftlich politische Verpflichtungen und Bündnisse. Feirefiz hat die Rolle als Grenzgänger zwischen Orient und Okzident im Blut, sie ist ihm in seiner Elsternfarbigkeit geradezu auf den Leib geschrieben, um die bereits zitierten Bilder noch einmal zu unterstreichen.

Jener bewegt sich nicht nur wie sein Vater in beiden Welten, im Orient und im Okzident, jener ist nicht nur wie sein Vater ein Liebling der Frauen, welcher zunächst eine schwarze (Secundille) und dann eine weiße Dame (die Gralsträgerin Repanse de schoye) heiratet, sondern er wechselt auch seine religiöse Identität: Er lässt sich schließlich taufen $(814,1-818,19)$. Die Nähe zum Christentum, die sich in der Tränentaufe und in den inneren Werten, der kiusche, seiner Mutter Belakane $(28,10-17)$ bereits gezeigt hatte, kommt - so ließe sich folgern - in Feirefiz, dem Sohn, zum sakramentalen Vollzug. Genealogisch gedacht, wird jener Mangel an Heil, in dem Belakane trotz ihrer inneren Vorbildlichkeit und ihrer äußerlichen Bereitschaft zur Taufe (56,2830) verharrte, eine Generation später, im Sohn Feirefiz ausgeglichen. Das Heidnische, Fremde, das mit Feirefiz in die Welt der Gralsgemeinschaft hineingetragen wird, geht mit dessen Taufe geradezu im Christlichen als dem Höherwertigen auf, so könnte man den Gedanken weiter treiben. Erst nach der Taufe gehört Feirefiz zum Kreis der Eingeweihten in der Gralsgesellschaft, erst als Getaufter kann er den Gral sehen und die Schrift, die temporär auf ihm erscheint $(818,20-23)$. Nur die Taufe, das zeigt die Episode am Gral, macht sehend im eigentlichen, im höheren Sinn. Eben darauf verweisen die Worte Titurels, des Ahnherrn der Gralssippe:

bliothek N.F. Reihe 3: Untersuchungen), S. 289-309 - Walter Delabar: Erkantiu sippe unt hoch geselleschaft. Studien zur Funktion des Verwandtschaftsverbandes in Wolframs von Eschenbach „Parzival“. Göppingen 1990 (Göppinger Arbeiten zur Germanistik 518) - Rolf E. SutTER: mit saelde ich gerbet han den gral. Genealogische Strukturanalyse zu Wolframs von Eschenbach „Parzival“. Göppingen 2003 (Göppinger Arbeiten zur Germanistik 705). 
der sprach, ist ez ein heidensch man,

sô darf er des niht willen hân

daz sin ougn âns toufes kraft

bejagen die geselleschaft

daz si den grâl beschouwen:

da ist hâmît für gehouwen. ' $(813,17-22)$

Im Bild des hâmît $(813,22)$, des Gestrüpps, Verhaus, welches dem Heiden gleichsam die Sicht auf den Gral versperrt, wird die Grenze zwischen dem Heiden und den Christen noch einmal deutlich markiert. Die Taufe des Feirefiz ist daher zentral im Blick auf die weiteren heilsgeschichtlichen Zusammenhänge, denn jener heiratet die Gralsträgerin Repanse de schoye und geht mit ihr nach Indien (Trîbalibôt), wo er das Christentum verbreitet $(822,21-823,10)$. Sein Sohn wird der Priester Johann, nach dem man auch alle späteren Könige des Landes benennen wird.

[Repanse de Schoye]

diu gebar sît in Indyân

ein sun, der hiez Jôhan.

priester Jôhan man den hiez:

iemmer sît man dâ die künege liez

bî dem namn belîben.

Feirefiz hiez schrîben

ze Indyâ übr al daz lant,

wie kristen leben wart erkant. (822, 23-30)

Der Kreis scheint sich geschlossen zu haben, wenn Feirefiz in den Orient, in das Land seiner mütterlichen Herkunft, zurückkommt, doch über die väterliche Verwandtschaft hat er Zugang zum Gral und damit zum Christentum erhalten, insofern kehrt er gewandelt zurück. In seinem Sohn, dem Priesterkönig Johann, verknüpfen sich wie sonst nur in Parzival erneut die Mazadan- und die Gralssippe, da Feirefiz eine Mutterschwester seines Halbbruders Parzival heiratet. Die genealogische Rolle des Priesters Johann deutet seine mögliche spätere Position als Gralskönig an, doch lässt der Roman diese Frage offen. ${ }^{33}$ Um den Gedanken zusammenzufassen: Die genealogische Verbindung von Belakane und Gahmuret sowie die Taufe des Feirefiz und seine Ehe mit Parzivals Tante haben den Weg gebahnt für die Missionierung Indiens, die Missionierung des Ostens. Damit wäre zu fragen, ob das genealogische Modell der Integration von Orient und Okzident nur aufgegriffen wird, um letztendlich die Dominanz des Christentums zu fundieren und damit den gewünschten gesellschaftlichen und religiösen Zustand bereits in der Naturordnung des Blutes zu antizipieren und zu verankern.

33 Der "Jüngere Titurel“ verdeutlicht dagegen, dass Johann der nächste Gralskönig wird; vgl. ebd., Str. 325; Str. 4834 sowie Str. 6122-6278. 
Der Text kann auf diese Spur führen, zieht man die Fäden der Erzählung von Feirefiz im beschriebenen Sinne aus, doch gerade wenn man die Handlung mit Wolframs eigenen Hinweisen zu seinen narrativen Techniken verknüpft ${ }^{34}$ wird klar, dass eine solche Interpretation zu kurz griffe, denn: Die großen, gerade akzentuierten heilsgeschichtlichen Zusammenhänge, die sich in Feirefiz und seinem Sohn zeigen, werden konterkariert durch die Inszenierung seiner Taufe. Jener begehrt nicht die Taufe, sondern die schöne Repanse, die Taufe ist ihm nichts als ein Mittel zur Liebeserfüllung (814,1-818,23). Er drängt zur Eile, um das Ziel seiner erotischen Wünsche zu erreichen, er lässt die Taufe als veräußerlichtes Ritual über sich ergehen, er möchte sie gar erkämpfen, so wie man sich als Ritter auch sonst im Kampf bewähren muss, um die Liebe und die Hand einer Dame zu erringen. ${ }^{35}$ Das Lachen Parzivals und Anfortas' quittiert die Komik der Szene (815,1-10). Nur um der Liebe zu Repanse willen ist Feirefiz bereit, seine erste Frau zu verlassen und Jupiter sowie allen anderen Göttern abzuschwören, worin schlaglichtartig auch die krude Vorstellung vom Islam als polytheistischer Religion deutlich wird (815,3-10; 816,25-30; $818,1-12) .{ }^{36}$

Die in der Romanwelt des „Parzival“ zentrale Differenz von außen und innen ließe sich im Blick auf Feirefiz veräußerlichte Taufe durch das Sakrament und Belakanes innere Nähe zum Christentum noch einmal unterstreichen. ${ }^{37}$ Die Komik der Taufe des Feirefiz stellt die Dominanz des Christlichen zwar nicht in Frage, doch sie raubt der Integration des Heiden ins Christentum den Ernst und relativiert in gewissem Sinne auch die große heilsgeschichtliche Linie, oder anders formuliert: In Feirefiz' Art, in seinem Blut, in der Farbe seiner Haut und in der von ihm ausgehenden Genealogie bleibt die heterogene Herkunft aus der Verbindung eines Christen und einer Heidin, die Spannung zwischen Ost und West erhalten. Auf eben diese Verschränkung der Gegensätze, des Wider-

34 Vgl. vor allem die Hinweise im Prolog $(1,1-4,26)$ und im sogenannten Bogengleichnis (241,1-30). Der Erzähler macht darauf aufmerksam, dass sein Text Haken schlägt und einen Rezipienten erfordert, der allen Wendungen und Umschlägen der Geschichte zu folgen bereit ist.

35 "Parzival“, 814,24-30: ,bruoder, umb die muomen dîn. | holt man den touf mit strîte, | dar schaffe mich bezîte $\mid$ und lâz mich dienen umb ir lôn. | ich hôrte ie gerne solhen dôn, | dâ von tjoste sprîzen sprungen | unt dâ swert ûf helmen klungen.'

36 Das Problem mit seiner ersten heidnischen Ehefrau Secundille löst sich durch die Nachricht von deren Tod (822,19 f.) dann ohnehin auf. Die Konstellation Secundille Feirefiz - Repanse erinnert an Gahmuret, der sich den Ansprüchen dreier Frauen ausgesetzt sah: Belakane - Ampflise - Herzeloyde. Im Wettstreit um die Gunst der Ritter unterliegen die Heidinnen jeweils den christlichen Damen.

37 Hier ist zu bedenken, dass Feirefiz' Tränen nach dem Wiedererkennen seines Bruders und der traurigen Erkenntnis, dass sein Vater tot sei, ihn bereits ganz analog zu den Tränen seiner Mutter Belakane in die Nähe des Christentums stellen. Vgl. „Parzival“, 752,24-26: sîn heidenschiu ougen | begunden wazzer rêren $\mid$ al nâch des toufes êren. 
sprüchlichen und Heterogenen würde ich auch das im Prolog erwähnte parrieren $(1,4$ : ,versetzen', ,mustern', ,mischen') beziehen. Es geht um die Verknüpfung des Heterogenen und Widersprüchlichen, nicht um deren Auflösung, nicht um deren Verschwinden. ${ }^{38}$

\section{VII}

Die Komplexität der Konstellationen lässt sich keiner einfachen und eindeutigen Auflösung aller Probleme zuführen. Dies gilt insbesondere auch für die Genealogien der Romanwelt, welche in Feirefiz und seinen Nachkommen Orient und Okzident umspannen und insofern geradezu universale Dimensionen gewinnen. Bei näherem Zusehen wird deutlich, dass damit sozusagen ein Spezialfall einer übergreifenden menschheitsgeschichtlichen Konstellation vorliegt, worauf jetzt näher einzugehen ist: In der epischen Welt des „Parzival“ wirken zwei genealogische Systematiken, welche sich zwar überschneiden, welche jedoch nicht zur Deckung zu bringen sind und auch unterschiedlich funktionalisiert werden können. Das Genealogische im engeren Sinne betrifft die Verwandtschaft einzelner Familien, die sich im Blick auf ihre Legitimierungsansprüche gerade von anderen Verbänden abheben müssen, ja durch ihre Differenz zu anderen Verwandtschaftsverbänden ausgezeichnet sind. Das Genealogische im weiteren Sinne zielt auf die Verwandtschaft aller Menschen als Kinder Gottes und Nachkommen Adams. Diese im christlichen Schöpfungsgedanken verankerte Vorstellung wiederum hat einen eher paritätischen Appell, welcher die beschriebenen Ansprüche auf Exklusivität und Abgrenzung gerade einzuebnen droht. Die Geltung der großen, der universalen Geschichte vom Ursprung der Welt und der Menschheit und die Geltung der partikularen Erzählungen von der Genealogie einzelner Gruppen überlagern sich.

Eben dies manifestiert sich im "Parzival" nicht nur in den genealogischen Konstellationen der erzählten Welt, sondern es wird im 9. Buch thematisch, als der Einsiedler Trevrizent, Parzivals Onkel, diesem zentrale heilsgeschichtliche Wahrheiten enthüllt. ${ }^{39}$ Trevrizent erläutert hier die Genealogie des Menschen-

38 Darauf verweist, so möchte ich akzentuieren, auch der offene Schluss des Romans, der nach dem Moment der Erlösung der Gralsgesellschaft durch Parzival neue Fragen aufwirft, ohne abschließende Lösungen zu bieten. Vgl. dazu vor allem Jолснім Bumke: Parzival und Feirefiz - Priester Johannes - Loherangrin. Der offene Schluss des „Parzival“ von Wolfram von Eschenbach. In: DVJs 65 (1991), S. 236-264; vgl. allgemeiner zur ,Offenheit' der Erzählwelt Manfred Eikelmann: Schanpfanzun. Zur Entstehung einer offenen Erzählwelt im „Parzival“ Wolframs von Eschenbach. In: ZfdA 125 (1996), S. $245-263$.

39 Die Perspektive des Trevrizent wurde lange Zeit in der Forschung als Kernaussage des Romans bewertet. Vgl. dazu Joаснім Bumke: Wolfram von Eschenbach. 8., völlig neu bearbeitete Auflage. Stuttgart/Weimar 2004, S. 89-93 mit weiteren Hinweisen sowie 
geschlechts von der göttlichen Schöpfung Adams her, was zugleich auf die genealogische Thematik der Erzählung verweist. Die Genealogie der Menschheit wird von Trevrizent nun als Heils- und Unheilsgeschichte zugleich erklärt. Neben dem Sündenfall Adams und Evas ${ }^{40}$ ist hier der Brudermord Kains an Abel zentral:

Kâins vater was Adâm:

der sluoc Abeln umb krankez guot.

dô ûf die reinen erdenz bluot

viel, ir magetuom was vervarn:

den nam ir Adâmes barn.

dô huop sich êrst der menschen nît:

alsô wert er immer sît. $(464,16-22)$

Jener Brudermord wird - Wolfram greift hier durchaus gängige theologische Interpretationen auf ${ }^{41}$ - zugleich als Schändung der Großmutter der Brüder gesehen. Indem Kain Abel tötet, nimmt er seiner Großmutter, der Erde, ihre Jungfräulichkeit, denn Abels Blut ergießt sich auf die Erde, die unschuldige und unberührte. Indem diese Besudelung mit dem Blut des Ermordeten als Verlust der Jungfräulichkeit gewertet wird, begeht Kain - in jener Perspektive - zwei genealogische Ursünden zugleich: Brudermord und Inzest. Diese Sünde - so die Logik von Trevrizents Ausführungen - zeugt sich über die Generationen hinweg von Mensch zu Mensch als Erbsünde fort, was Trevrizent im mythischen Bild vom Sündenwagen zusammenfasst: unt daz diu sippe ist sünden wagen, | sô daz wir sünde müezen tragen (465,5 f.). Damit ist die genealogische Unheilsgeschichte bezeichnet, doch die Genealogie des Menschengeschlechts bedeutet zugleich auch die geschichtliche Entfaltung des Heils, da der Erlöser, Christus, der nach und in typologischer Beziehung zu Adam zweite Jungfrauensohn ebenfalls in das Verwandtschaftssystem integriert ist. Heil wie Unheil aller Menschen auf der Welt leiten sich also genealogisch von Adam her:

Von Adâmes künne

huop sich riwe und wünne,

sît er uns sippe lougent nibt,

S. 119 f. Trevrizents Ausführungen werden jedoch durch seine merkwürdigen Bemerkungen nach Parzivals Erlösung der Gralsgesellschaft deutlich relativiert. Trevrizent bezichtigt sich selbst der Lüge und missversteht Parzivals Erlösung der Gralsgesellschaft, indem er äußert, jener habe Gott den Gral abgetrotzt und ihn im Kampf erstritten. Vgl. 798,1-30, besonders 1-8: Trevrizent ze Parzivâle sprach |, groezer wunder selten ie geschach, | sît ir ab got erzürnet hât $\mid$ daz sîn endelôsiu Trinitât $\mid$ iwers willen werhaft worden ist. | ich louc durch ableitens list $\mid$ vome grâl, wiez umb in stüende. | gebt mir wandel für die süende: [...].'

40 „Parzival“, 463,19-23: von Adâms verhe er Even brach, | diu uns gap an daz ungemach, | dazs ir schepfare überhôrte | unt unser freude stôrte. | von in zwein kom gebürte fruht.

41 Vgl. Nellmann: Kommentar (wie Anm. 14), S. 675, mit weiteren Hinweisen. 
den ieslîch engel ob im siht,

[...]. (465,1-4)

In dieser universalen Konstruktion wird jeder Mensch zum Verwandten, kann jeder als Bruder des anderen aufgefasst sein. Als Konsequenz zeichnet sich ab: Die Perspektivierung von Handlungen, insbesondere von Konflikten und Kämpfen, kann in der epischen Welt des „Parzival“ changieren, je nachdem, in welcher genealogischen Reichweite man sie primär situiert und bewertet. Was im Rahmen der Vorstellungen von Genealogie im engeren Sinne legitim und möglich erscheint, der Kampf gegen Nichtverwandte, wie Heiden, wird - im Modell der universalen Menschheitsgenealogie perspektiviert - zum Problem. Wenn auch der Fernste, der Heide, als ein Bruder in der Verwandtschaft von Adam her aufgefasst werden kann, werden Kämpfe prinzipiell fragwürdig. ${ }^{42}$ Und eben dies wird in der paradigmatischen Reihe von Verwandtenkämpfen im „Parzival“ sichtbar gemacht.

Der Protagonist kämpft gegen seinen Verwandten Ither, den er tötet, ohne seine Genealogie zu kennen (155,1-11), er kämpft auch gegen die Verwandten Vergulaht $(424,15-425,14)$ und Gawan $(679,1-680,30 ; 688,5-690,2)$ und schließlich gegen seinen Bruder, den gescheckten Heiden Feirefiz $(738,1-$ $745,8)$. Als mächtiger Heide, der aus dem Orient kommt, ist Feirefiz Parzival fern, doch der Ferne ist der Nächste, ist sein Bruder. In der Konfrontation zwischen Parzival und Feirefiz im Kampf werden beide genealogischen Reichweiten, die ich analytisch differenzierte, enggeführt. Im Sinne der universalen Genealogie ist jeder Heide mit jedem Christen verwandt, doch hier begegnen sich zugleich Verwandte im engeren Sinne, und der Erzähler weist auf diesen Konnex hin, lange bevor die Brüder sich erkennen: ieweder des andern herze truoc: | ir vremde was heinlîch genuoc. (738,9 f.). Gott ist es, der Parzivals Schwert im Kampf zerspringen lässt und der damit die Wiederholung der genealogischen Ursünde verhindert, die Wiederholung von Kains Totschlag an Abel. ${ }^{43}$

von Gaheviez daz starke swert mit slage ûfs heidens helme brast, sô daz der küene rî̀che gast

mit strûche venje suochte.

got des niht langer ruochte,

daz Parzivâl daz rê nemen

in siner hende solde zemen:

daz swert er Ithêre nam,

als siner tumpheit dô wol zam. $(744,10-18)$

$42 \mathrm{Vgl}$. dazu auch die Problematik der Heidenkämpfe in Wolframs "Willehalm“.

43 Vgl. zur Thematik des Verwandtenkampfes Wolfgang Harms: Der Kampf mit dem Freund oder Verwandten in der deutschen Literatur bis 1300. München 1963 (Medium aevum 1). 
Der Erzähler macht deutlich, dass es sich um eben jenes Schwert handelt, das Parzival einst Ither, dem von ihm getöteten Verwandten abgenommen hatte (744,17 f.). So verweist ein Verwandtenkampf auf den anderen, und so steht die friedliche Beilegung des Kampfes der Brüder gegen Ende des Romans dem tödlichen Ausgang des Kampfes mit Ither gegenüber. Indem Feirefiz auf weitere Kämpfe gegen seinen unbewaffneten Bruder verzichtet $(747,1-18)$, wird sein vorbildliches ritterliches Ethos unterstrichen. Wie das Genealogische erweist sich - hier und an anderen Stellen des Romans - also auch das HöfischRitterliche als Verbindung von Heiden und Christen, als Modell der fairen Konfliktregulation und der Integration jenseits der religiösen Differenz.

Der besondere Fall eines Kampfes zwischen dem Christen Parzival und dem Heiden Feirefiz zeigt als Ausdruck der universalen Genealogie des Menschengeschlechts die Gefahr und Problematik des Kampfes - bezogen auf beide genealogischen Ordnungen. Das Zerspringen des Schwertes, das Niederlegen der Waffen, bedingen die Möglichkeit, den anderen zu erkennen und weisen im Romanverlauf zugleich die Richtung im Blick auf den weiteren Erlösungsweg Parzivals. ${ }^{44}$ Das Erfahren des anderen, des Fremden und des Heiden wird in der Begegnung der Brüder von Wolfram zugleich als Auseinandersetzung mit sich selbst inszeniert. ${ }^{45}$ Der Erzähler fokussiert diesen Aspekt, indem er betont, dass sich in Feirefiz und Parzival e in Leben, e in Fleisch und Blut, gegenüberstehen:

Daz ich die rede mac niht verdagen,

ich muoz ir strît mit triwen klagen,

sit ein verch und ein bluot

solch ungenâde ein ander tuot.

si wârn doch bêde eins mannes kint,

der geliutrten triwe fundamint. (740,1-6).

Der über das Blut gegebene enge Konnex der Familienmitglieder wird von Wolfram hier und an anderen Stellen des Romans im Sinne einer Identität eines

44 Es wäre allerdings eine zu vorschnelle Lektüre des Textes, glaubte man, dass diese friedliche Beilegung des Bruderkampfes grundsätzlich für ein Ende des Kämpfens stehe. Es ist vielmehr eine Momentaufnahme aus der Geschichte der Helden und damit jener der Mazadan- und Gralssippe, durch welche das Ethos des Kampfes nicht aus der Welt geschafft wird. Die Kampflust des Feirefiz scheint ungebrochen zu sein, wie gerade sein Verhalten bei der Taufe zeigt (814,24-30), und auch die der Erlösung des Grals angehängte Geschichte von Parzivals Sohn Loherangrin zeigt, dass es weitere Kämpfe geben wird (826,7 f.). Der Text des „Parzival“ kommt auch in anderen Beziehungen nicht an ein Ende: Die Erlösung der Gralsgesellschaft erscheint ebenfalls als ein glücklicher Moment, der jedoch nicht für die Lösung aller Probleme steht. Vgl. Bumke (wie Anm. 38), S. 236-264.

45 Der Gedanke, Fremdverstehen erfolge über das Verstehen des Selbst, ist in der phänomenologischen Tradition zentral. An dieser Stelle sei nur verwiesen auf Sснüтz (wie Anm. 11), S. 137-197. 
Familien- respektive Verwandtschaftskörpers akzentuiert. ${ }^{46}$ Und dies wiederum wird von Feirefiz nach der Anagnorisis der Brüder und nachdem er vom Tod seines Vaters erfahren hat, als quasi trinitarische Spekulation der Verwandtschaftsbezüge ausgesponnen.
,ich hân an disen stunden
freude vlorn und freude funden.
wil ich der wârheit grîfen zuo,
beidiu mîn vater unde ouch duo
und ich, wir wâren gar al ein,
doch ez an drîen stücken schein.
swâ man sibt den wîsen man,
dern zelt decheine sippe dan,
zwischen vater unt des kinden,
wil er die wârheit vinden.
mit dir selben hâstu hie gestritn.
gein mir selbn ich kom îf strît geritn,
mich selben het ich gern erslagn:
done kundestu des niht verzagn,
dune wertest mir min selbes lìp.' (752,5-19)

Dazu passen komplementär die bereits erwähnten heilsgeschichtlichen Anklänge bei Parzivals Geburt. Über das Stillen des neugeborenen Knaben setzt sich Herzeloyde selbst in Beziehung zur Mutter des Jesuskindes $(113,18-114,4) .{ }^{47}$ Die Genealogie der Familie wird damit rückgebunden an die zentralen heilsgeschichtlichen Geheimnisse der Trinität und der Geburt des Erlösers. Auf diese Weise wird Parzivals Rolle als Erlöser der Gralsgesellschaft in die Nachfolge Christi und dessen Erlösung des Menschengeschlechts gestellt. Dies wiederum gilt zumal, da die Genealogie der Familie über die Verschränkung mit der universalen Genealogie der Menschheitsgeschichte auf die Schöpfung Adams durch Gott zurückgeführt wird und dessen Geburt ihrerseits mit der Geburt Christi analogisiert ist. Schöpfung und Inkarnation werden damit in die Inszenierung des genealogischen Gesamtzusammenhangs eingebunden, was die heilsgeschichtliche Dimension der Parzival-Handlung unterstreicht.

46 Vgl. „Parzival“, 740,26-30, noch einmal im Blick auf Parzival und Feirefiz: man mac wol jehn, sus strîten sie, | der se bêde nennen wil ze zwein. | si wârn doch bêde niht wan ein. mîn bruodr und ich daz ist ein lîp, | als ist guot man unt des guot wîp. Vgl. dazu auch die Akzentuierung der Identität von Vater und Sohn durch Herzeloyde bei Parzivals Geburt. 109,24-110,1: ,ich was vil junger danne er [Gahmuret], | und bin sin muoter und sîn wîp. | ich trage alhie doch sînen lîp | und sînes verhes sâmen. | den gâben unde nâmen | unser zweier minne. | hât got getriwe sinne, | sô lâzer mirn ze frühte komn.' Vgl. auch $110,10-22$.

47 Vgl. dazu Abschnitt V dieses Beitrags mit dem Verweis auf Bertau (wie Anm. 27), S. 259-285. 


\section{VIII}

Erscheinen die genealogischen Konstellationen des Romans geradezu auf die Verschränkung von Orient und Okzident, Heidnischem und Christlichem angelegt, so ist unter diesen Aspekten auch Wolframs Inszenierung der Herkunftsgeschichte seines Textes von zentraler Bedeutung. Erst im Epilog des Romans nennt der Erzähler seine eigentliche Vorlage, Chrétiens de Troye „Conte du Graal“, er nennt sie, um sie abzuwerten und sich auf jenen von ihm mehrfach erwähnten Vorgänger zu berufen, der bekanntlich nirgendwo nachweisbar ist, den Provenzalen Kyot. ${ }^{48}$ Kyot, nicht Chrétien, habe die richtige Geschichte geboten, er - Wolfram - wolle nichts über das hinaus hinzufügen, was jener Meister gesprochen habe. ${ }^{49}$ Das Muster der Legitimierung des eigenen Textes über die Berufung auf Quellen wird damit aufgegriffen, doch im Modus der Abweisung der eigentlichen Quelle und der Fiktion einer vermeintlichen Quelle konterkariert. ${ }^{50}$ Metaphorisch könnte man komplementär zu den ge-

48 Kyot wird im „Parzival“ an folgenden Stellen erwähnt: 416,20-30; 431,1-4; 453,1455,$22 ; 776,8-10 ; 805,10 ; 827,1-18$.

49 Vgl. „Parzival“, 827,1-14: Ob von Troys meister Cristjân | disem mare hât unreht getân, | daz mac wol zürnen Kyôt $\mid$ der uns diu rehten mere enbôt. | endehaft giht der Provenzâl | wie Herzeloyden kint den grâl | erwarp, als im daz gordent was, | dô in verworhte Anfortas. | von Provenz in tiuschiu lant $\mid$ diu rehten mare uns sint gesant, | und dirre aventiur endes zil. | niht mêr dâ von nu sprechen wil | ich Wolfram von Eschenbach, | wan als dort der meister sprach.

50 Die ältere Forschung versuchte vergeblich, Kyot als historischen Autor auszumachen. Die meisten neueren Forschungsbeiträge gehen von einer Quellenfiktion aus. Vgl. zum sogenannten Kyot-Problem etwa Walter J. Schröder: Kyot. In: GRM N.F. 9 (1959) S. 329-350 - Herbert Kolb: Munsalvaesche. Studien zum Kyotproblem. München 1963 - Walter FalK: Wolframs Kyot und die Bedeutung der, Quelle i im Mittelalter. In: Literaturwissenschaftliches Jahrbuch N.F. 9 (1968), S. 1-63-CARL Lofmark: Zur Interpretation der Kyotstellen im „Parzival“. In: Wolfram-Studien IV (1977), S. 33-70 - Wolfgang Mohr: Wolframs Kyot und Guiot de Provins. In: Ders.: Wolfram von Eschenbach. Aufsätze. Göppingen 1979 (GAG 275), S. 152-169 - UlRICH ERnST: Kyot und Flegetanis in Wolframs „Parzival“. Fiktionaler Fundbericht und jüdisch-arabischer Kulturhintergrund. In: Wirkendes Wort 35 (1985), S. 176-195 - HerberT Kolb: Guido militiae Templi magister. In: Archiv für das Studium der neueren Sprachen und Literaturen 223 (1986), S. $337-344$ - Eberhard Nellmann: Wolfram und Kyot als vindare wilder mare. Überlegungen zu „Tristan“ 4619-88 und „Parzival“ 453,1-17. In: ZfdA 117 (1988), S. 31-67 - RüDIGER SCHüTZ: Die Echos der Verschwiegenheit. Ein semiotischer Zugang zum Kyotproblem in Wolfram von Eschenbachs „Parzival“. In: Osnabrücker Beiträge zur Sprachtheorie 42 (1990), S. 168-185 - Ulrike DraEsNER: Wege durch erzählte Welten. Intertextuelle Verweise als Mittel der Bedeutungskonstitution in Wolframs „Parzival“. Frankfurt a. Main/Berlin/Bern u. a. 1993 (Mikrokosmos 36), S. 381-409 - Bumke (wie Anm. 39), S. 89, 209 u. 244-247 - Klaus Ridder: Autorbilder und Werkbewußtsein im „Parzival“ Wolframs von Eschenbach. In: Wolfram-Studien XV (1998), S. 168-194, hier S. 181-188 - Peter Strohschneider: 
nealogischen Konstellationen der Romanhandlung von einer Genealogie des Textes sprechen, die über den Heiden Flegetanis und den Christen Kyot auf den Erzähler und die âventiure führt. ${ }^{51}$ Akzentuiert man die Herkunftsgeschichte in diese Richtung, wird deutlich, dass es sich um ein hybrides Konstrukt handelt, in welchem verschiedene Erzählinstanzen auf komplexe Weise verknüpft werden und heidnische und christliche Momente eine Rolle spielen. Erzählt wird die Geschichte vom Gral und dessen Ursprung und diese führt auf den Heiden Flegetanis und seine Kunst, in den Sternen zu lesen. Flegetanis wird als fisîôn $(453,25)$ dargestellt, als Naturforscher, ${ }^{52}$ und im Zuge der Genealogie des Textes wird auch seine eigene Herkunft enthüllt:

Mütterlicherseits stammte er aus einer alten jüdischen Familie, die bis in vorchristliche Zeit zurückreichte und sich von Salomon ableitete (453,26 f.), väterlicherseits sei er ein Heide gewesen, der ein Kalb als Gott verehrte, was abwertend als Verführung durch den Teufel dargestellt wird (454,1-8). ${ }^{53} \mathrm{Hy}$ brid wie die Geschichte der Erzählung vom Gral stellt sich damit auch die Abstammung dieses Gelehrten dar. Als Astronom wusste Flegetanis nach Wolframs Darstellung um die Sternenkonstellationen, er wusste ieslîches sternen hinganc | unt siner künfte widerwanc; | wie lange ieslîcher umbe gêt, | $\hat{e}$ er wider an sîn zil gestêt (454,11-14), - gemeint sind hier wohl die Umlaufbahnen der Planeten, ihre Deszendenzen und Aszendenzen. Kraft seiner astronomischen Fähigkeiten habe er in den Sternen mit seinen Augen das Geheime und Verborgene, verholenbariu tougen $(454,20)$, gesehen, wovon er nur mit Scheu, blûweclîche $(454,18)$, zu sprechen wagte. Der Ursprung der Geschichten vom Gral wird solchermaßen von Wolfram in den Bereich eines Mysteriums gerückt, welches in der Schau eines heidnischen Astronomen erschlossen wird. Die Sternenkonstellation ihrerseits wird als Ausdruck göttlichen Willens entworfen, in ihr zeige sich sein Ratschluss und sie habe Einfluss auf das Schicksal der Menschen. ${ }^{54}$ Mittels seiner astronomischen Kenntnisse konnte der Heide daher nach Wolframs Bericht einen Blick in heilsgeschichtliche Tatsachen werfen. Hier ist noch einmal auf die Genealogie des Gelehrten zu verweisen, denn genealo-

Sternenschrift. Textkonzepte höfischen Erzählens. In: Wolfram-Studien XIX (2006), S. 33-58, hier S. 47-56.

51 Zu dem schwierigen Verhältnis zwischen Kyot, der âventiure und dem Erzähler siehe die näheren Ausführungen bei BEATE Kellner: ein maere wil iu niuwen. Spielräume der Fiktionalität in Wolframs von Eschenbach „Parzival“. In: Konzepte der Fiktionalität und die Kulturen des Mittelalters. Hg. von Ursula Peters/Rainer Warning, im Druck.

52 fisî̂n hängt wohl mit lat. physicus zusammen. Vgl. zu Flegetanis' Fähigkeiten in der Astronomie „Parzival“ 454,9-30.

53 Vgl. dazu „Exodus“, 32,1-35. Wann Flegetanis gelebt hat, lässt sich nicht genau bestimmen. Vgl. dazu Nellmann: Kommentar (wie Anm. 14), S. 667.

54 Vgl. „Parzival“, 454,15 f. Im Roman werden diese Beziehungen an zentralen Stellen sichtbar, denn die Sternenkonstellationen bestimmen sowohl Anfortas' Leidensgeschichte (489,24-30) wie Parzivals Gralsberufung (782,5-30). 
gisch betrachtet ist er ein Grenzgänger und als solcher prädestiniert, Zugang zu verschiedenen Welten zu haben und Wissen zwischen jenen zu vermitteln. Nun ist es höchst umstritten und wahrscheinlich nicht auflösbar, was Flegetanis in den Sternen gesehen haben soll. Er kann den Namen des Grals und seine Kenntnisse über die Gralshüter wohl aus einer bestimmten Sternenkonstellation erkennen: ${ }^{55}$

er jach, ez hiez ein dinc der grâl:

des namen las er sunder twâl

inme gestirne, wie der hiez.

,ein schar in ûf der erden liez:

diu fuor ûf über die sterne hôch.

op die ir unschult wider zôch,

sît muoz sin pflegn getouftiu frubt

mit alsô kiuschlìcher zuht:

diu menscheit ist immer wert,

der zuo dem grâle wirt gegert.' $(454,21-30)$

Wolframs Text bleibt dunkel und rätselhaft, indem er jene Mysterien beschreibt, und eben dies scheint kein Zufall zu sein, sondern die Art des Erzählens ist dem Beschriebenen adäquat. Vom Ursprung des Grals und seiner Geschichte wird erzählt, doch er bleibt zugleich entzogen und geheimnisvoll. Für den weiteren Traditionsprozess ist es entscheidend, dass Flegetanis das in den Sternen Gesehene in Buchstaben gefasst und aufgezeichnet haben soll. Sus schreip dervon Flegetânîs $(455,1)$, heißt es im Text. Der Christ Kyot habe - unbestimmte Zeit danach - in Toledo, einem Zentrum jüdischer, christlicher und arabischer Gelehrsamkeit, schließlich diesen vergessenen ursprünglichen Text in heidnischer, wohl arabischer Schrift gefunden:

Kyôt der meister wol bekant

ze Dôlet verworfen ligen vant

in heidenischer schrifte

dirre âventiure gestifte.

der karakter $\hat{a} b c$

muoser hân gelernet $\hat{e}$,

an den list von nigrômanzî. $(453,11-17)$

Im Unterschied zu Flegetanis habe er, nachdem er die Schrift- und Zauberzeichen ${ }^{56}$ gelernt habe, ohne dabei auf die schwarze Kunst zurückzugreifen, den Text nicht nur sehen und entziffern können, sondern als Getaufter habe er die Geschichte des Grals auch verstanden. Die Taufe erscheint mithin als conditio sine qua non, um die Geheimnisse des Grals zu entdecken, seine Sinndimen-

55 Vgl. Nellmann: Kommentar (wie Anm. 14), S. 668 - Strohschneider (wie Anm. 50), S. 53-55.

56 Vgl. Nellmann: Kommentar (wie Anm. 14), S. 666, der karacter als Zauberzeichen versteht - dazu Strohschneider (wie Anm. 50), S. 51-53. 
sionen zu erschließen: ez half daz im der touf was bî: | anders war diz mar noch unvernumn. | kein heidensch list möht uns gefrumn | ze künden umbes grâles art, | wie man siner tougen inne wart (453,18-22). Flegetanis kommt die Rolle des Tradenten zu, der die Zeichen der Sternenkonstellation in Schrift übersetzt hat, Kyot ist der eigentliche Hermeneut. Insofern ist der Blick des Flegetanis in die Sternenkonstellation kein ,Einblick' in die Heilsgeschichte im eigentlichen Sinn. Insofern werden heidnische Astronomie und Gelehrsamkeit gegenüber christlicher Hermeneutik ausgespielt. Somit werden heidnische und christliche Aspekte in der Inszenierung der Herkunft der Gralsgeschichte vereint, um doch wieder gegeneinander abgesetzt zu werden. Und dennoch gehören sie zu dieser Geschichte der Erzählung dazu, denn ohne den Heiden Flegetanis und seine ersten Aufzeichnungen in der Schrift hätte Kyot jene nicht deuten können.

Wenn Kyot sodann nach Belegen für die Geschichte des Grals in lateinischen Büchern, in den Chroniken verschiedener Länder, gesucht und diu mare mit der Genealogie der Mazadan- und der Titurelsippe schließlich in Anschouwe gefunden haben soll $(455,2-22)$, wird die Geschichte von der Herkunft des Textes noch mit einem zweiten Traditionsstrang verknüpft: den in Anschouwe ganz offensichtlich in Schrift- und Buchform vorliegenden Erzählungen. Über diese hybride, christliche und heidnische Aspekte umfassende Geschichte vom Ursprung und den Überlieferungen der Texte wird auch der Gral selbst in die Nähe heidnischer Gelehrsamkeit und Sternenkunde gerückt.

Dies bestätigt sich noch einmal in der Rede, mit welcher Cundrîe Parzival seine Berufung zum Gral eröffnet $(781,11-782,30)$, denn sie, die sich in der Astronomie auskennt (312,24f.), nennt die arabischen Planetennamen (782,6$12)^{57}$ und will auf diese Weise deutlich machen, dass die Planetenkonstellationen nun günstig für Parzival sind. Solchermaßen werden Parzivals Schicksal und der Gral wiederum zu heidnischer Sternenkunde in Beziehung gesetzt und diesem werden damit kosmische Dimensionen unterstellt. ${ }^{58}$

Der Gral bleibt im „Parzival“ nicht nur für den Protagonisten bei seiner ersten Einkehr in Munsalvaesche rätselhaft (235,15-240,30), sondern auch nach den Erläuterungen Trevrizents im 9. Buch $(469,3-471,29) .{ }^{59}$ Er bleibt ebenso rätselhaft wie seine Benennung, er heizet lapsit exilliss (469,7). Er ist ein Stein, der Wunder wirkt, der ganz im Sinne eines ,Tischlein-deck-dich' auf magische Weise Speisen hervorbringt $(238,8-17)$. Wer ihn ansieht, kann nicht

57 Vgl. dazu Paul Kunitzsch: Die Planetennamen im „Parzival“. In: ZfdtSpr. 25 (1969) S. 169-174 - Ders.: Arabica (wie Anm. 13), S. 28 f. Vermutlich bedient sich Wolfram lateinischer Übersetzungen arabischer Fachliteratur. Die Forschung geht davon aus, dass Wolfram rudimentäre, vulgarisierte astronomische, astrologische Kenntnisse zum Besten gibt.

58 Vgl. Bumke (wie Anm. 39), S. 117 f.

59 Eine gute Übersicht über die verschiedenen Traditionen vom Gral bietet: VolkeR Mertens: Der Gral. Mythos und Literatur. Stuttgart 2003. 
sterben und behält jugendlich frisches Aussehen $(469,14-28)$, ihm wohnt also die Kraft zur Regeneration inne. Nur durch die Kraft des Steines vermag sich daher auch der Vogel Phönix zu erneuern, wie Trevrizent berichtet $(469,8-13)$. Zugleich ist der Gral auf das Engste mit der Heilsgeschichte verbunden, mit den Geschicken der beim Sündenfall neutralen Engel (471,15-29). Seine magischen Kräfte erneuern sich alljährlich aus seinen unmittelbaren Bezügen zur Transzendenz, wenn die weiße Taube ihm am Karfreitag eine feine weiße Oblate bringt (469,29-470,20). Nur die Besten sind berufen, den Gral zu hüten $(235,25-30 ; 470,21-471,14)$, und besonders eng ist jener mit der Genealogie des Titurelgeschlechts verknüpft. Sein Erscheinen ist eingebunden in strenge höfische Rituale (231,1-240,30). Die magische, am Gral erscheinende Schrift (470,21-30), die nur Christen zugänglich ist, verweist wiederum auf das Mysterium des Gralsnamens in den Sternen. In summa verkörpert der Gral alles, was man auf Erden wünschen kann, er ist der wunsch von pardîs $(235,21)$, erden wunsches überwal $(235,24)$, die Frucht des Heils, der salden frubt $(238,21)$, der Inbegriff des Süßen auf der Welt: der werlde süeze ein sölh genuht $(238,22)$. Beinahe hält er dem die Waage, was man vom Himmelreich erzählt: er wac vil nâch gelîche | als man saget von himelrîche (238,23 f.). Mithin ist der Gral der Fluchtpunkt alles Wünschens und Begehrens, welcher die Handlung der erzählten Welt immer wieder in Bewegung bringt und in Gang hält, ja welcher letztendlich als Ermöglichungsgrund der erzählten Welt erscheint. In seinen Immanenz- und Transzendenzbezügen, der aggregativen Spannung von christlichen, heidnischen, mythischen, magischen und höfischen Momenten ist er die Hybride par excellence.

\section{IX}

Im Rahmen dieses Beitrags können unmöglich alle Dimensionen ausgeschöpft werden, in denen das Heidnische im „Parzival“ zum Tragen kommt. Erwähnen möchte ich hier noch, dass Heiden gerade bei den zentralen Gefährdungen der Gralsgesellschaft eine gewichtige Rolle spielen. So wird der Gralskönig Anfortas während seiner âventiure im unerlaubten Minnedienst $(478,1-480,2)$ von einem Heiden, der den Gral in seinen Besitz bringen will, ${ }^{60}$ mit einem vergifteten Speer an den Hoden, durch die heidruose $(479,12)$, so verwundet, dass er nicht mehr gesunden kann, es sei denn durch die erlösende Frage eines Ritters (480,3-484,30). Jener Heide trifft die Gralsgesellschaft damit in ihrem Zentrum, da er die Zeugungsfähigkeit des Gralskönig zerstört, er gefährdet die

60 „Parzival“, 479,18-24: der selbe heiden was gewis, | sîn ellen solde den grâl behaben. | inme sper was sîn nam ergraben: | er suocht die verren ritterschaft, | niht wan durch des grâles kraft | streich er wazzer unde lant. | von sîme strîte uns freude swant. 
Genealogie der Gralskönige und er lähmt damit die Lebensfähigkeit der gesamten Gralsgesellschaft. ${ }^{61}$

Anfortas' Geschichte wiederum lässt sich auf jene Clinschors beziehen (656,3-657,26), denn auch dessen Unheil nimmt seinen Ausgang von einer unerlaubten Liebe, seinem Ehebruch mit der sizilischen Königin Iblis. Dieser zieht eine schwere Strafe nach sich, denn Clinschor wird vom Ehemann der Königin zwischenn beinn gemachet sleht $(657,21)$, er wird kastriert durch einen Schnitt $(657,20-25)$. Da es ihm damit unmöglich wird, weiterhin die Liebe zu genießen, sinnt er darauf, durch Zauberkunst die Freude anderer zu zerstören $(657,26)$. Als Nachkomme Vergils steht Clinschor in der genealogischen Linie dieses im Mittelalter als Zauberer und Prophet interpretierten Heiden. ${ }^{62}$ Nach seiner Kastration verlegt er sich auf die Zauberkunst und fährt in jene Stadt mit dem Namen Persida, in der diese ihren Ursprung haben soll. ${ }^{63}$ Dort im Heidenland erlernt er die Zauberkunst so, daz er wol schaffet swaz er wil, | mit listen zouberlîchiu zil (658,1f.), und er setzt seine magischen Fähigkeiten zum Schaden der Menschen ein.

Dies zeigt sich insbesondere auf seiner Burg Schastel marveile, wo sich nicht nur besondere magische Objekte finden wie das Zauberbett Lit marveile $(567,1-569,25)$ und die Wundersäule $(589,27-590,16 ; 592,1-20),{ }^{64}$ sondern wo zahlreiche Menschen, Christen und auch Heiden, von Clinschor gefangen gehalten werden $(558,12-27 ; 659,1-30)$. Clinschor erzeugt auf diese Weise einen Zustand ohne Liebe, ohne Fruchtbarkeit auf Schastel marveile, der wiederum auf den unerlösten Zustand der Gralsgesellschaft verweist. Ähnlich bezieht sich Gawans Erlösung dieser magischen Welt dann auf Parzivals Erlösung der Gralsgesellschaft. Gerade im Vergleich von Munsalvaesche und Schastel marveile wird deutlich, dass sich in und um Clinschor, der im zweiten Buch des "Parzival“ auch als phaffe, der wol zouber las $(66,4)$, bezeichnet wird, die negativen Aspekte des Heidnischen und Magischen bündeln. Sie stellen sozusagen die Schattenseite des Heidnischen dar und sind in der Welt Clinschors und auf seiner Burg Schastel marveile situiert.

61 Es sei daran erinnert, dass Anfortas' Schicksal über seinen Hochmut bzw. den Mangel an dêmuot $(479,1)$ auf Parzival verweist.

62 „Parzival“, 656,15-18: von des nâchkomn er ist erborn, | der ouch vil wunders het erkorn, | von Nâpels Virgilîus. | Clinschor des neve warp alsus.

63 Das Land Persien wird hier gegen die lateinische geographische Tradition als Stadt missverstanden. Vgl. Nellmann: Kommentar (wie Anm. 14), S. 742.

64 Mit ihrer Hilfe kann man die Umgebung im Umkreis von sechs Meilen beobachten $(592,13)$. 
Es dürfte aus den hier analysierten Konstellationen deutlich geworden sein, wie komplex die Thematik des Heidnischen in Wolframs Roman verhandelt wird. Immer wieder verschränken sich Heidnisches und Christliches, spannungsvoll werden sie integriert, ohne dass ihre Gegensätzlichkeit und Widersprüchlichkeit aufgehoben wird. Keinesfalls lassen sich Heidnisches und Christliches in einer Dichotomie von gut und böse auflösen. Das Heidnische wird in seinen Verbindungen mit dem Christlichen immer wieder neu perspektiviert, häufig erscheint es ambivalent. Und bei näherer Betrachtung wird schließlich offenkundig, dass selbst das Christliche sich als hybrid erweist. Auch in ihm manifestieren sich heidnische und christliche Momente, welche immer wieder auch über die Klammer des Höfischen verbunden sind. In ganz besonderem Maße sichtbar wird dies in der Chiffre des Grals.

Im Spätmittelalter werden diese Konstellationen Wolframs aufgenommen und bearbeitet. Zentrale Zeugnisse dieser Rezeption sind neben dem "Jüngeren Titurel“ jene Überlieferungen, welche man unter dem Titel „Wartburgkrieg“ bündeln kann. Sie zeigen die Arbeit an Wolframs Texten, sie zeigen vor allem auch die Arbeit an Wolframs Verschränkungen von Heidnischem und Christlichem, denn der pfaffe, der wol zouber las $(66,4)$, Wolframs Romanfigur Clinschor, wird jenem als Kontrahent Klingesor von Ungerlant gegenübergestellt. Dieser erscheint sogar als Autor des gesamten "Wartburgkrieges“, wie in der „Heidelberger Liederhandschrift“, oder zumindest als Autor des Schwarzen Tons, wie in der „Kolmarer Liederhandschrift“. Im sogenannten „Rätselspiel“ und in "Zabulons Buch" sowie in anderen Teilen des "Wartburgkrieg-Komplexes" treten Wolfram und Klingsor in einem Wissens- und Erzählwettstreit gegeneinander an. Hier werden die Grenzen von Heidnischem und Christlichem neu verhandelt, hier geht es um den Zugang zu heilsgeschichtlichen Tatsachen ebenso wie um den Zugriff auf Magie und Negromantie, hier werden heidnisches und christliches Wissen gegeneinander abgegrenzt. Wolframs Rolle wird immer wieder als jene des frommen Laien bestimmt, während Klingsor als meisterpfaffe erscheint, der seine Ausbildung im Orient erhalten hat, zeitweise Anhänger Mahomets war und auch über schwarzmagische Künste verfügt. Die Rolle Wolframs wird hier in der Abgrenzung von Klingsor tariert, als Rolle des frommen Laien wird sie gereinigt von den Überschreitungen und Uneindeutigkeiten, welche den großen epischen Texten Wolframs eignen. ${ }^{65}$

65 Ich verweise hier auf die Arbeiten aus den von Peter Strohschneider und der Verfasserin geleiteten Forschungsprojekten zum "Wartburgkrieg-Komplex“. Vgl. etwa BEATE Kellner/Peter Strohschneider: Die Geltung des Sanges. Überlegungen zum „Wartburgkrieg“ C. In: Wolfram-Studien XV (1998) S. 143-167 - DIES.: Wartburgkriege. Eine Projektbeschreibung. In: Deutsche Texte des Mittelalters zwischen Hand- 
schriftennähe und Rekonstruktion. Berliner Fachtagung 1.-3. April 2004. Hg. von Martin J. Schubert. Tübingen 2005 (Beiheft zu Editio), S. 173-202 - Dies.: Poetik des Krieges. Eine Skizze zum „Wartburgkrieg“-Komplex, in: Das fremde Schöne. Dimensionen des Ästhetischen in der Literatur des Mittelalters. Hg. von ManuEl Braun/ Christopher Young, Berlin/New York 2007 (Trends in Medieval Philology 12), S. 335-356. 